\title{
EL DILEMA DEL PROGRESISMO JURÍDICO: SOBRE LA PERTINENCIA DE UN EJERCICIO CRÍTICO DEL DERECHO
}

\section{Luciana Alvarez ${ }^{1}$}

\section{Resumen}

El artículo propone una reflexión sobre aquello que Duncan Kennedy, fundador de la Critical Legal Studies (CSL) habría diagnosticado como el dilema del progresismo jurídico, a través del cual apuntaba a la situación en la que se encontraba la posibilidad y potencialidad política de la crítica a los derechos, en el modo como resultó expuesta en aquel conocido trabajo "La crítica de los derechos en los Critical Legal Studies". Para ello mostraremos algunas limitaciones de la propuesta de Kennedy e intentaremos problematizar la posibilidad y necesidad de un ejercicio crítico en el campo jurídico a partir de algunos de los desarrollos de Foucault respecto de las relaciones de poder, el gobierno y la conducción de conductas.

Palabras Clave: Crítica; Progresismo Jurídico; Interpretación; Decisión Judicial; Gubernamentalizad.

\section{LA CRÍTICA EN LOS TRABAJOS DE DUNCAN KENNEDY: UNA CARACTERIZACIÓN DEL DILEMA DEL PROGRESISMO JURÍDICO²}

Este trabajo se concibe como un diálogo crítico. Tomará simplemente la forma de un cruce de perspectivas, de cuya productividad espero poder dar cuenta. Como sugiere el título que hemos asignado a nuestro trabajo, proponemos una reflexión sobre aquello que Duncan Kennedy habría diagnosticado como el dilema del progresismo jurídico, a través del cual apuntaba a la situación en la que se encontraba la posibilidad y potencialidad política de la crítica a los derechos. Este dilema aparece presentado y desarrollado en aquel conocido trabajo "La crítica de los derechos en los Critical Legal Studies" (2006) ${ }^{3}$. El problema conforme lo sitúa el autor es: en la medida en que la crítica de los derechos contribuye a una pérdida de fe en ellos, lo que incluiría la pérdida de la posibilidad de ser utilizados como estrategias de resistencia a la opresión de los sectores más

\footnotetext{
${ }^{1}$ Doctora en Derecho con mención en Filosofía del Derecho pela Universidad Nacional de Cuyo, Argentina. Profesora en las cátedras de Filosofía del Derecho e Introducción a la Filosofía da Facultad de Derecho da Universidad Nacional de Cuyo, Argentina. Investigadora Adjuta del Consejo Nacional de Investigaciones Científicas y Tecnológicas - CONICET de Argentina. Email: lalvarezbauza@gmail.com

${ }^{2}$ Una versión preliminar fue presentada bajo el título "El dilema del progresismo jurídico: reflexiones sobre el por qué o el hasta dónde del ejercicio crítico”, Taller sobre la obra del Prof. Duncan Kennedy, XXX Jornadas de la Asociación Argentina de Filosofía del Derecho "Derecho, Política y Educación", 2, 3 y 4 de noviembre, 2016, Universidad Nacional de Buenos Aires (UBA).

${ }^{3}$ Originalmente publicado en inglés Kennedy, D., “The Critique of Rights in Critical Legal Studies” (2002).
} 
desaventajados (en términos de explotación, marginalidad, discriminación, etc.), llevar a cabo la tarea de la crítica de los derechos supone el riesgo de socavar las bases mismas de nuestras posibilidades de disputa y, eventuales, victorias políticas. Esto es así, incluso para los defensores de un liberalismo político más o menos robusto: no importa cuán repugnante a mis preferencias personales sea el contenido de una norma, el problema radica en que debe respetarse la autoridad del derecho puesto que en ello radica, eventualmente, la defensa o protección de las libertades humanas y ello constituye un valor en sí mismo.

Si esto es así: ¿Por qué realizar una crítica de los derechos? Como tal, esta reflexión del autor se enmarca en una lectura retrospectiva de los Critical Legal Studies que los sitúa en relativa distancia tanto de la izquierda tradicional como del posmodernismo o deconstruccionismo cercanos al feminismo y los estudios poscoloniales, en sus múltiples versiones. La CLS es una corriente de pensamiento que se desarrolló en la academia norteamericana a finales de los años $1970^{4}$. De acuerdo a cómo lo expone Kennedy, la crítica que desarrollan los $C L S^{\prime}$ “... opera en una incómoda intersección entre dos empresas distintas con frecuencia complementarias pero a veces en conflicto, que denominaré el proyecto de la izquierda y el proyecto modernista-postmodernista..." (2006: 178)

De acuerdo con Kennedy, los derechos en general y los derechos humanos en particular juegan un rol fundamental en la conciencia jurídica y política norteamericana. Ellos son el fundamento, la base, tanto de proyectos ideológicos liberales como de proyectos ideológicos conservadores (2006: 48). Esta doble pertenencia simbólica de los derechos a un amplio espectro de idearios políticos, que suponen a su vez diversas formas de concebir la sociedad, los individuos que la conforman y las relaciones sociales que se articulan en su interior, genera una ambivalencia fuerte: no resulta fácil desarrollar una crítica de los derechos en relación a los modos en que ellos son funcionales a un sistema de explotación y desigualdad, puesto que ello podría suponer el desconocimiento de su potencial para la disputa política en diversos ámbitos, como lo han mostrado distintos movimientos sociales (trabajadores, mujeres, migrantes, colectivos identitarios, etc.) desde los años 60' en adelante, en Estados Unidos, lo que además ha sido teorizado por diversas vertientes de la teoría crítica. En este contexto, la crítica de los derechos que desarrollaron los Critical Legal Studies (CLS) resultaba problemática puesto que, conforme lo entendieron los teóricos/as feministas y los de la critical race theory, los derechos realmente existían o debían existir y era desmoralizante criticarlos (2006: 52). Es decir, si es posible que los derechos jueguen un rol relevante en las prácticas políticas contemporáneas permitiendo la inclusión de

\footnotetext{
${ }^{4}$ Conviene tener en cuenta que no se trató de un fenómeno aislado ni precursor. Sino que, para el mismo periodo surgieron, en diversas latitudes (Europa, Latinoamérica), escuelas o perspectivas críticas respecto al derecho, cuya conformación puede caracterizarse a partir de los distintos elementos que las posibilitaron.
} 
numerosas reivindicaciones de grupos identitarios explotados y/o marginados: por qué insistir en destruir sus fundamentos racionales ... tal actitud supone asumir el riesgo de perder nuestras propias armas frente a nuestros oponentes políticos (2006: 83). Es preciso aclarar que la modalidad de la interrogación asume, por sí misma, la posibilidad de que el discurso de los derechos pueda resultar operativo para una política emancipatoria o libertaria, cuestión, por lo demás, muy debatida.

En el desarrollo del problema de la crítica de los derechos, Kennedy pretende mostrar por qué, entonces, resulta necesario, deseable y/o posible realizar el tipo de crítica que proponen los Critical Legal Studies. Aun cuando la crítica de los derechos "... no es la solución a ningún problema de la izquierda, ni una panacea, ni un programa y dado que las consecuencias para la militancia y el compromiso son en el mejor de los casos inciertas ..." (2006: 84) existen razones para disponerse a esa tarea. De acuerdo con Kennedy, las razones pueden enunciarse así: es necesario cuestionar todo discurso, o representación, con pretensiones universales de objetividad y corrección. Los derechos o el discurso de los derechos funcionan dentro del proyecto global de la corrección moral burguesa (racional y trascendental) que estructura las formas contemporáneas de patriarcado racista y capitalista. El discurso de los derechos es altamente efectivo dentro de la conciencia jurídico-política norteamericana porque permite definir ese umbral de corrección objetiva, definiendo la frontera entre lo subjetivo (meras preferencias, que pueden corresponder con derechos externos exigibles más allá de encontrarse positivados) y lo objetivo (hechos incontrovertibles, positivos, derechos que han sido reconocidos como tales por la autoridad política y conforme los procedimientos previstos). Esto es así en la medida en que el discurso de los derechos funciona como mediación entre diversos ámbitos: los derechos son factoides en el sentido que median entre los valores y los hechos; y por otro lado, los derechos constitucionales median entre los derechos internos o positivados y los derechos externos. Así, “... el razonamiento basado en los derechos, en suma, te permite tener razón respecto a tus juicios de valor, en vez de tener meras 'preferencias' ...” (2006: 53). En ese sentido opera con firmeza el principio, estructural de la teoría liberal y cierto republicanismo, según el cual no debería confundirse el derecho vigente en una sociedad con los valores vigentes en ella ya que, aun cuando puedan coincidir y de hecho los sistemas de derecho modernos coinciden con el repertorio de estándares mínimos de corrección moral propios de una filosofía política liberal, se trata de ámbitos estrictamente heterogéneos y por ello podemos defender la validez y aplicación de una norma que nos resulte repugnante, aun cuando el rechazo a lo consagrado en la norma presente razones igualmente válidas. Así, el discurso de los derechos funciona sin mayores problemas dentro del horizonte simbólico del sistema de explotación y desigualdad patriarcal, racista y capitalista. Y, en ese sentido, es polémica la afirmación según la cual es necesario preservarlos de la crítica. Los derechos son

\footnotetext{
5 "This rights critique, like critical legal studies in general, operates at the uneasy juncture of two distinct, sometimes complementary and sometimes conflicting enterprises, which I will call the left and the modernist/postmodernist projects"
} 
fuertemente ideológicos al presentarse como expresión de la objetividad y corrección moral, siendo en realidad la expresión de determinadas concepciones de verdad y moralidad: el discurso de los derechos tiene por función regular e inducir las conductas sociales en una determinada dirección y con arreglo a fines coyunturales y precisos.

No resulta posible defender el carácter objetivo del derecho, y en consecuencia es igualmente imposible desentrañar la verdad objetiva y universal de un discurso determinado, sea un discurso jurídico u otro. Por ello, ante la imposibilidad de fidelidad interpretativa cabe preguntarse qué es posible o deseable hacer en nuestras intervenciones estratégicas y concretas una vez que hemos "perdido la fe" en los derechos como estándares objetivos y universales de corrección pero nos encontramos igualmente comprometidos con la transformación progresista de la sociedad en que vivimos. ¿Qué es esperable que haga un juez, por ejemplo, en la medida que cobra plena conciencia del carácter intrínsecamente ideológico del discurso jurídico? ¿Qué tipo de discurso jurídico-político podría promoverse desde una posición alternativa y comprometida con el carácter emancipatorio de los derechos sin renunciar a la crítica? De acuerdo con Kennedy, no sería factible desde la perspectiva de la izquierda/mpm promover el desarrollo de otra teoría que se erija como correcta: si el problema del discurso de los derechos es suponer la existencia de un estándar de corrección moral y asumirse como garante del mismo, una posición alternativa debería evitar caer en las mismas inconsistencias del discurso liberal de los derechos.

Esta ambivalencia se explicita en todo su esplendor en relación a la decisión judicial: el discurso de los derechos funciona como una imposición externa y objetiva ante el libre arbitrio del juzgador. Los jueces, en su gran mayoría, presentan sus decisiones como producto exclusivo de la aplicación del razonamiento jurídico aun cuando se trate de sus preferencias personales, ya que el discurso de los derechos les permite disimularlas. En estos casos el discurso de los derechos como estándar de corrección moral funciona sin mayores obstáculos. De acuerdo con Kennedy, las intervenciones estratégicas remiten a una experiencia individual y sólo pueden ser analizadas a ese nivel: “... parece obvio que cualquiera sea el factor que decide el resultado, no es la aplicación correcta de un razonamiento jurídico (...) Esto no significa que el razonamiento jurídico nunca produzca un cierre. Puede hacerlo, pero cuando ello sucede, experimentar este hecho no implica, para una persona que ha perdido la fe, que dicho cierre estuviera basado en algo que está "allí afuera", algo a lo que el razonamiento jurídico hiciera referencia. Simplemente fue una experiencia, y podría haber terminado de otro modo (si uno hubiera seguido otra línea de trabajo, por ejemplo)...” (2006: 59). Lo que lleva al intérprete que es consciente de esta ausencia de corrección objetiva, el juez por ejemplo, a sostener “... ahora siento que el proceso es algo que yo hago a los materiales para que produzcan el resultado que quiero. A veces funciona y a veces no; esto es, a veces obtengo el resultado que quiero y a veces no..." (2006: 59).

(traducción de Bertomeu, J., op. cit.). 
La posición de Kennedy, opuesta a aquella más tradicional según la cual el juez resuelve conforme a derecho y se encuentra limitado y constreñido por el contenido de la normas o materiales jurídicos, aun cuando pretende mediar entre la tesis de la discrecionalidad irrestricta del juez y la tesis que se apoya en la existencia de límites infranqueables, continua dentro de un modelo que supone la existencia de una voluntad individual por un lado y de límites normativos por el otro. Ello le permite sostener la tesis según la que, desde el punto de vista fenomenológico, en el proceso de decisión el juez experimenta tanto la libertad como la restricción frente a los materiales normativos. El juez percibiría que "... a esta altura de mi vida ya poseo un conjunto de intenciones, con un proyecto vital como juez, y estos factores se encargarán de orientarme entre las muchas posibles actitudes a seguir ...” (1999: 104). El juez de Kennedy aparece así como un sujeto consistente y completo, propietario de un proyecto vital y capacidad de acción que enfrenta el trabajo de interpretación y decisión con un adecuado control del proceso que le permite en muchos casos, a través de diversas elecciones posibles, obtener los resultados que esperaba.

\section{DE LA IMPOSIBLE INDIVIDUALIDAD DE LAS INTERPRETACIONES: POR QUÉ INTERPRETAR ES NECESARIAMENTE UN HECHO SOCIAL}

En la forma en que el autor presenta el funcionamiento de las intervenciones interpretativas, para aquel agente que ha perdido su fe en la corrección u objetividad de los derechos, parecería operarse un desplazamiento de la pretendida -e ideológica- corrección inherente a los derechos a la pérdida de todo referente más o menos racional que permita comprender y hacer explícito cómo funciona el discurso del derecho, para desde allí generar deslizamientos, torsiones, desvíos más o menos transformadores. La posición de Kennedy supone que las intervenciones políticas que anudan proyectos políticos y estándares normativos, resultan fundamentalmente individuales, personales, y se sostienen a partir de la experiencia que supone atravesar un proceso en el que interactúan de diversos modos: la solución interpretativa que el intérprete decide (la sentencia a la que yo quiero llegar) (1999, 93-97) y la solución que brinda la ley. Así, en sus análisis respecto a la decisión judicial aparece reiteradamente la idea de que a menudo los jueces producen un significado convincente para los materiales jurídicos, que es distinto del significado que otros jueces, con una agenda de trabajo opuesta, habrían producido (2010,34). Una intervención estratégica, en este sentido estaría determinada por una preferencia individual del intérprete, del hecho de adscribir a un proyecto político liberal o conservador, por ejemplo, así como una gran cantidad de opciones más o menos aleatorias y decidibles a nivel individual.

En relación a ello nos interesa poner de relieve que una reducción individualizante del análisis crítico respecto de los derechos resulta problemática. Aun cuando compartimos la necesidad de realizar un ejercicio crítico respecto de los derechos, o del discurso del derecho, encontramos problemáticas algunas localizaciones 
teóricas del autor que parecerían asumir el proceso de intervención estratégica como una experiencia sobre todo individual, lo que supondría desconocer el anclaje del derecho -o el discurso de los derechos- en las prácticas sociales que lo hacen posible y que, como tales, responden a una racionalidad que les es inherente. Por supuesto no se trata del razonamiento jurídico en el modo en que se concibe tradicionalmente. Estamos convencidos que "la sentencia a la que yo quiero llegar" que se representa el juez a la hora de proponer una interpretación, se corresponde con el contexto socio-histórico en el que esa representación emerge. No se trata de una preferencia del juez que debe tornarse admisible para un auditorio determinado, a la manera en que ello podría ser pensado desde algunas perspectivas de la argumentación jurídica. Sino, y tal como refirió Enrique Marí, hace algo más de 30 años, respecto de la verdad en el proceso judicial: “... La verdad del resultado no es una verdad metafísica, no hay verdad ni por descubrimiento de la esencia del sistema ni por des-encubrimiento (aleteia heideggeriana). Tampoco es una verdad verificacionista en el sentido de un enunciado comprobado por ciertos hechos de una base empírica social, ni una verdad por consistencia o coherencia entre un enunciado y el resto del sistema jurídico. Es una verdad producto de una lucha en el seno de una relación conocimiento-poder. Pero de ningún modo constituye una verdad irracional ( ... Es, al contrario, una verdad "redondamente" racional. Representa "la racionalidad" de una sociedad en un momento dado de su desarrollo ..." (1982, 76). En el mismo texto Marí muestra cómo en el marco de un proceso judicial se ponen en funcionamiento una serie de mecanismos de control y habilitación que no responden a procedimientos jurídicos propiamente, mucho menos a los deseos del juzgador, sino a las dinámicas sociales: se trata de mecanismos de control que disponen los modos y los tiempos en que puede un discurso ingresar, permanecer $y$ salir de un determinado expediente, $y$ de este modo determinan la cara legible del discurso jurídico $(1982,58)$. Marí muestra cómo la incorporación de diversos peritajes psiquiátricos sobre el condenado respondía a coyunturas propias de la psiquiatría, las diferentes concepciones de enfermedad mental en pugna y la emergencia de un paradigma que requería de validación. Una sentencia judicial, al igual que el texto de la ley que prosigue un trámite legislativo determinado, explican su contenido a partir de las relaciones sociales y relaciones de poder que se encuentran en acción en unas determinadas coordenadas espaciotemporales. Por ello, no podría decirse que una sentencia, en cuanto texto legal, deba su contenido a la voluntad del juez estrictamente, si ello implica sostener la existencia de una voluntad ajena a codificaciones sociales. En cierta medida, la voluntad así como las preferencias personales del juez no existen más que como la cristalización de aquello que resulta posible en un espacio y tiempo determinados.

Esta posición no supone privarlas de toda virtualidad, pero sí relativizar su peso específico en relación al contenido de la decisión. Y ello no sólo porque el juez se encuentre constreñido por el auditorio al que se dirige y debe -idealmente- convencer acerca de la adecuación a derecho de la sentencia que él mismo suscribe, sino porque sus mismas preferencias, deseos, prioridades, convicciones resultan de una configuración espacio 
temporal, en la medida en que no pueden comprenderse fuera de ella. Como señalaremos más adelante en referencia a los desarrollos de Foucault, como deseo o preferencia emergen en el campo de acciones posibles que habilitan las codificaciones capaces de producir, en los sujetos que se subjetivan, una serie de aptitudes, de disposiciones voluntarias, de conductas. En este sentido: el constreñimiento nos constituye, por ello no es posible trabajar con los materiales sino a través del trabajo con nosotros mismos. Una crítica posible y necesaria en relación al discurso de los derechos involucra una problematización de la posición político-interpretativa del juez, tornando inestable incluso su voluntad de juzgar, pues el acto de mismo de juzgamiento comprende una serie de materialidades que se encuentran ajenas a su albedrío. Así, "la sentencia a la que quiero llegar" no emerge de su voluntad creadora, en tensión con la autoridad legal de los materiales jurídicos, como así tampoco supone efectos necesarios, deseados o no deseados. Pues, una vez introducidos en un campo de fuerzas los efectos que suscite dependen de las correlaciones que articule: “... no hay poder que se ejerza sin una serie de miras y objetivos. Pero ello no significa que resulte de la opción o decisión de un sujeto individual ( ... la racionalidad del poder es la de las tácticas a menudo muy explícitas en el nivel en que se inscriben -cinismo local del poder- que encadenándose unas con otras, solicitándose mutuamente y propagándose, encontrando en otras partes sus apoyos y su condición, dibujan finalmente dispositivos de conjunto..." (Foucault, 1977, 115).

No podríamos hablar de algo como la discrecionalidad judicial frente al límite impuesto por el derecho: en el ámbito de la decisión judicial operan una multiplicidad de estrategias que configuran un campo de acciones posibles. Se trata de estrategias que podríamos identificar como jurídicas así como correspondientes a otras dimensiones y todas ellas codifican las conductas, aptitudes, intereses, deseos del intérprete o juez, en su caso.

\section{UNA ENTRADA FOUCAULTEANA A LOS PROBLEMAS DEL DERECHO: ACTITUD CRÍTICA Y PRÁCTICAS DE RESISTÊNCIA}

En cierta medida, aquello que conocemos habitualmente como derecho (leyes, principios jurídicos, sentencias) corresponde a prácticas sociales, relaciones de poder, codificaciones sociales determinadas. La ley no supondría la materialización de verdades objetivas ni trascedentes: el discurso de los derechos es eminentemente histórico. Intentaremos mostrar, además, que el discurso de los derechos, o la realidad de lo jurídico, es inmanente a las relaciones de poder propias de una sociedad determinada e irreductible, por ello, a la idea de voluntad creadora, sea individual o colectiva. Para ello proponemos, retomando algunos elementos que introdujimos en el acápite precedente, una entrada a partir de los desarrollos de Foucault de acuerdo con los que el derecho, lo jurídico, puede comprenderse como parte del diagrama de poder de una sociedad determinada: en el caso de nuestras sociedades contemporáneas, y de acuerdo con la perspectiva foucaulteana, el diagrama de poder biopolítico en su modulación (neo)liberal. 
El derecho, como conjunto normativo, funcionaría como una actualización -institucionalización- de la exposición de fuerzas que se encuentran actuando en un campo determinado, y sólo es comprensible a partir del diagrama de poder de una sociedad en una determinación espacio-temporal. Esta posibilidad de lectura en los trabajos (escritos y cursos) de Foucault en relación al discurso del derecho se enmarca en un debate, iniciado a comienzos de los años $90^{\prime}$, sobre el modo en que habría concebido lo jurídico y que estuvo fuertemente marcado por la ausencia -en esos años- de ediciones y traducciones de sus trabajos posteriores a Vigilar y castigare Historia de la sexualidad Vol. I. La voluntad de saber ${ }^{7}$. Los cursos dictados en el College de France han sido editados y publicados en francés a partir del año 1997, luego traducidos a distintos idiomas. La lectura y análisis que siguieron a estas ediciones han renovado el debate y permiten otras preguntas y posibles respuestas en torno de lo jurídico y las relaciones de poder en los desarrollos de Foucault.

Como es bien conocido, y de acuerdo con Foucault, las relaciones de poder no son reductibles al consenso ni a la violencia (Lemke, 2012, 17-20): no se trata de saber qué es el poder, sino de saber cómo funciona. El funcionamiento del poder, a partir del siglo XVIII es capilar, y se extiende en diversos sentidos en la trama de nuestras sociedades, por lo tanto circula, no está ni aquí ni allá, no tiene centro. Esta racionalidad, o diagrama, exige comprender el derecho, o la ley, más allá del nivel global, más allá del efecto de conjunto que la ley supone. Desde el punto de vista microfísico, es decir desde la perspectiva del poder, lo jurídico involucra, como advierte Deleuze: “... sus decretos de aplicación y sus casos de interpretación ...”: es inseparable de ellos porque la ley es en realidad la resultante, la composición, de los ilegalismos. La ley constituye la gestión o repartición de los ilegalismos en un campo social (Deleuze, 2014, 61-63). Como tal, como composición de ilegalismos, la ley nunca es el producto de una estrategia individual: sino de las relaciones de fuerzas que se encuentran en funcionamiento en un diagrama determinado. Y son estas relaciones las que condicionan el campo de acciones posibles, para todos los individuos, incluidos los jueces y operadores jurídicos. Los casos de interpretación, las decisiones judiciales, en tanto estrategias de intervención constituyen puntos de apoyo del poder: de algún modo el poder circula, pasa, a través de esas instancias y en esa circulación creemos que lo poseemos, creemos que como intérpretes poseemos el poder de decidir de una manera u otra.

Lo que intentaremos mostrar en el desarrollo que sigue a continuación es cómo la función judicial, y entonces también la decisión judicial, forma parte de una determinada racionalidad de gobierno. Cómo la

\footnotetext{
${ }^{6}$ Para una caracterización de este debate, sesgado a la academia angloparlante, puede verse: Golder, Ben and Fitzpatrick, Peter (2009), Foucault's law. New York: Routledge.

${ }^{7}$ Para una consulta introductoria sobre la recepción de Kennedy de los trabajos de Foucault puede verse: "The Stakes of Law, or Hale and Foucault!" Legal Studies Forum, Volume XV, Number 4 (1991), pp. 327-366. Conviene tener presente que los cursos dictados en el Collège de France a partir de 1976 comenzaron editarse en francés hacia fines de 1990 y algunos cursos de trascendencia para el problema de Foucualt y el derecho, se han editado en idioma original en los últimos tres años (Faire mal, dire vraiy Théories et institutions pénales).
} 
decisión judicial constituye una posición singular en el diagrama de relaciones de poder que involucran dispositivos disciplinarios y securitarios (o de regulación) a través de los que se conducen, se gestionan conductas. El diagrama de poder biopolítico se caracteriza por la configuración, a través de diferentes prácticas y dispositivos de regulación que exceden ampliamente lo jurídico, de un campo posible de acciones individuales y colectivas. Las nociones de biopolítica y gubernamentalidad no se circunscriben a la esfera global del gobierno de los otros, es decir desde el punto de vista de la población, sino también al nivel del gobierno de las conductas, dentro de la esfera del individuo.

Para comprender esto es necesario tener en cuenta que, de acuerdo con Foucault, habría operado a partir de mediados del siglo XVII un desplazamiento del poder de soberanía hacía la biopolítica -o biopoder-. De acuerdo con el viejo poder de soberanía, cuyo funcionamiento podemos situar entre los siglos XVI y mediados del XVIII, el derecho funcionaba como límite externo del poder político y garantizaba a su vez un ámbito de libertad individual para el desarrollo de la vida de los sujetos a quienes se "dejaba vivir". A partir de la transformación que señala Foucault, en relación a las sociedades de normalización: el gobierno toma a cargo la vida de los individuos y conjuntos poblacionales disciplinando y regulando sus cuerpos y capacidades vitales. El derecho deja de funcionar como límite externo, al haber cambiado las relaciones de fuerzas: el derecho enmascara relaciones de poder disciplinarias y reguladoras.

Pero, y este uno de los grandes y menos reconocidos aportes de Foucault, lo jurídico opera más allá de este nivel ideológico, las disciplinas -por ejemplo- se materializan a través de procedimientos institucionales tendientes a reglamentar, a escala administrativa y particular, los postulados jurídicos liberales. Pero, es en su funcionamiento, en el mecanismo que ponen en juego, en la forma en que gestionan su elusión, que develan su diagrama disciplinario; garantizando segregaciones y jerarquizaciones al "... distribuir lo viviente en un dominio de valor y de utilidad...” (1977, 174). Es así que “...En apariencia, las disciplinas no constituyen otra cosa más que un infraderecho. (...) Es preciso más bien ver en las disciplinas una especie de contraderecho. Desempeñan el papel preciso de introducir unas disimetrías insuperables y de excluir reciprocidades. ( ... ) la manera en que está impuesta, los mecanismos que pone en juego, la subordinación no reversible de los unos respecto de los otros, el "exceso de poder" que está siempre fijado del mismo lado, la desigualdad de posición de los diferentes "miembros" respecto del reglamento común oponen el vínculo disciplinario y el vínculo contractual, y permite falsear sistemáticamente éste a partir del momento en que tiene por contenido un mecanismo de disciplina." (2002, 225-7). Así, sólo podemos comprender la ley a partir de comprender cómo funcionan los poderes de normalización, que constituyen el subsuelo, de las libertades formales (2002, 226). En Historia de la sexualidad Vol. I. La voluntad de saber, lo expone de este modo: “... No quiero decir que la ley se borre ni que las instituciones de justicia tiendan a desaparecer; sino que la ley funciona siempre más como una 
norma, y que la institución judicial se integra cada vez más en un continuum de aparatos (médicos, administrativos, etc.) cuyas funciones son sobre todo reguladoras..." (1977, 175). El poder judicial funciona, entonces, como una institución integrada a un dispositivo específico como es la disciplina y la regularización -o securitización-

Lo que Foucault propone es una clave de lectura de las relaciones sociales en la que el derecho deja de ocupar el centro: el derecho aparece (des)centrado, en algunos casos subordinado, a las relaciones de fuerzas. Pero ello no supone de ningún modo que el derecho quede excluido en los desarrollos de Foucault, sino que es necesario una estructura conceptual, una grilla de inteligibilidad distinta de aquella que podía funcionar para las sociedades, que él mismo denomina, sociedades de soberanía.

De igual manera, unos años después, al consolidar la noción de gubernamentalidad, especialmente en los cursos de 1979 bajo el título Nacimiento de la biopolítica, Foucault mostrará cómo funciona el derecho en la racionalidad de gobierno neoliberal, a través del principio del Estado de derecho. La primacía del Rule of Lawen la gubernamentalidad neoliberal lejos de restaurar el viejo derecho de soberanía, constituye una de las formas singulares en que el derecho pone en acción mecanismos de sometimiento. La configuración del arbitraje judicial o seudo-judicial, como dispositivo de resolución de conflictos sociales, en detrimento de instancias políticoadministrativas que fueron dominantes en las diversas formas del Estado de bienestar, constituye una de las formas en que lo jurídico opera. La función judicial estaría desempeñando un rol estructural dentro del programa neoliberal de gobierno: constituye la forma de resolución de conflictos una vez que la planificación social ha sido desplazada por el libre juego de los planes de vida individuo-empresariales.

Esta entrada foucaulteana a los problemas del derecho nos permite caracterizar, o enmarcar, social y políticamente las intervenciones de los jueces, así como de otros intérpretes, más allá de sus preferencias o experiencias personales. En ese sentido contribuye a comprender por qué es posible para un determinado juez llegar a una determinada sentencia, asumiendo que esa posibilidad no se reduce a una elección personal, por justificada que ella pueda estar, sino que es producto "además" de las condiciones que la hacen posible. De ninguna manera ello supone sostener algún tipo de determinismo -que ha sido habitual en las lecturas superficiales de la obra de Foucault- sino de comprender que toda resistencia forma parte de aquellas relaciones de poder, y no se encuentra por fuera de ellas. De modo que, si es necesario pensar en formas de resistencia o intervención política en términos progresistas, éstas no pueden pensarse como algo exterior al mismo poder que nos produce como individuos. No podría, en este sentido, pensarse en un juez ejerciendo una voluntad externa, contraria, a los materiales jurídicos: la función judicial se encuentra ella misma al interior de las dinámicas de relaciones que definen la ley, como efecto de conjunto, en un campo social determinado. Y es preciso considerar, además, que la función judicial presenta una especial significación en las sociedades contemporáneas en que funcionan algunos 
elementos de la racionalidad de gobierno neoliberal.

Nos acercamos con esto a la posibilidad de una actitud crítica ${ }^{8} \mathrm{o}$ ana práctica de libertad que permite, al tiempo que determinadas técnicas nos codifican, ejercer otras que nos desujecionan... De algún modo, con nuestro señalamiento estamos proponiendo ir un poco más atrás: cómo construye el juez la sentencia a la quiere llegar y analizar esa elección en términos de agenciamiento, es decir, en términos de intervención estratégica en un campo de fuerzas en movimiento a fin de determinar cómo, y hasta dónde, comprometerse con sus intervenciones interpretativas. ¿Cómo y hasta dónde ejercitar la crítica de los derechos?

Retomemos entonces la función judicial en el diagrama de relaciones de poder que caracterizan a la gubernamentalidad neoliberal. Las reglas de derecho, a diferencia del viejo diagrama de soberanía, no indicarían el límite al poder del soberano, o al menos no exclusivamente, sino el marco de previsibilidad del juego indefinido y libre de los intereses. Si cada uno de los individuos participa del mercado como un núcleo empresarial, como gestor de sus recursos innatos y adquiridos, en competencia con otros individuos-empresa, nos encontramos frente a un tipo de conflictividad distinto de aquel que podía mostrar el intercambio en el que el Estado se ocupaba de arbitrar y operar distribuciones entre empleadores, trabajadores y, a su vez, redistribuía recursos de distinto tipo poniendo en juego estrategias político-administrativas. La competencia requiere un marco formal en el que las unidades empresariales desarrollan su juego libremente: la igualdad consiste en la existencia de este marco (Rule of Law) que garantice que todos los ciudadanos podrán reclamar igual respeto a su plan de vida racional (proyecto empresarial). De acuerdo con Foucault, las prácticas en que se materializa esta concepción de individuo-sociedad es la que acompaña la emergencia de la teoría del Estado de derecho o del Rule of Law. A diferencia del Estado de bienestar, se trata ahora, y ante la ausencia de una planificación general o social, de gestionar las planificaciones individuo-empresariales: “... el verdadero sujeto económico es la empresa. Cuanto más se anima a ésta a que haga su juego como considere en el marco de las reglas formales, más se fija por sí misma libremente sus propios objetivos, dando por supuesto que no hay ningún fin común impuesto..." (Laval y Dardot, 2013, 181-182). La necesidad de contar con un aparato judicial capaz de garantizar el imperio de la ley será crucial para gobernar, en la medida que permitirá a cada uno desarrollar su plan de vida y desarrollar y potenciar su capital humano, a resguardo de las interferencias arbitrarias de otros individuos y del mismo Estado.

El principio del Rule of Law supone que el Estado brinda reglas de juego formales para el desarrollo de los intereses de los jugadores (individuos subjetivados según la forma empresa). A través de los tribunales de justicia establece y garantiza las condiciones de posibilidad para el desarrollo de las libertades individuales, pero al hacerlo no brinda una forma, un marco vacío de contenido que podremos completar o rellenar a partir de nuestras

\footnotetext{
${ }^{8}$ En un trabajo reciente referimos detalladamente en qué consistiría una actitud crítica como forma de resistencia (Vignale y AUTOR/A, 2016: 164-182).
} 
elecciones libres. Por el contrario, nuestros intereses no son espontáneos ni se encuentran ajenos al cálculo. El mercado, en tanto espacio de veridicción, es el encargado de codificar el contenido de nuestras elecciones personales: queremos, deseamos en un ambiente, en un campo de deseos y elecciones posibilitado por el mercado. El mercado en tanto espacio de veridicción transcribe sus verdades en términos de derecho. En este sentido las libertades e intereses que protege el gobierno son "determinadas" libertades e intereses. Los individuos interesados concebidos como capital humano tenderán a desarrollar aquellas habilidades que redundan, directa o indirectamente, en recursos o ventajas económicas. En este escenario el poder judicial es el encargado de gestionar los posibles conflictos de estas unidades empresariales en competencia por desarrollar y desplegar habilidades, capacidades y potencialidades. Y al hacerlo compartirán una determinada representación de sí mismos como agentes institucionales. Esta representación, que hace posible que un juez pueda encontrar o escoger una "solución" específica para su caso constituye una elección relativa al diagrama de relaciones de poder que la habilitan: como tal no responde a un mandato legal, exclusivamente, como así tampoco al ejercicio pleno de su libertad reflexiva y/o afectiva. Las tendencias jurisprudenciales pueden comprenderse en correlación a patrones de probabilidad y normalidad, histórica y coyunturalmente determinados. En el campo de las acciones posibles determinadas por la gubernamentalidad neoliberal, se desarrollan entre muchas otras acciones la intervención estratégica de los jueces: una vez que advertimos el rol de la función judicial en el diagrama de relaciones de poder contemporáneas, la caracterización de la decisión del judicial como mera experiencia del juzgador que puede resultar satisfactoria, o no, en virtud del proyecto vital al que él mismo adscriba, parece ciertamente problemática. Esta caracterización, que Kennedy ha denominado fenomenológica, no parece decirnos mucho acerca del modo en que el derecho opera en nuestras sociedades para a partir de allí, generar o profundizar prácticas de resistencia y transformación... en todo caso, sí permite hacer observable cómo el juez, al igual que diversos agentes, se encuentran codificados en la medida que se perciben a sí mismos como portadores legítimos de un proyecto vital.

A partir de aquí podemos pensar en un ejercicio de la crítica de los derechos, en el marco de la interpretación y decisión judicial, que suponga a su vez estrategias de resistencia. En términos foucaulteanos es posible pensar en prácticas de libertad relativas a la gubernamentalidad, es decir, prácticas de resistencias en relación al modo en que somos gobernados. Puesto que “... si la gubernamentalización es este movimiento por el cual se trataba, en la realidad misma de una práctica social, de sujetar a los individuos a través de unos mecanismos de poder que invocan una verdad, pues bien, yo diría que la crítica es el movimiento por el cual el sujeto se atribuye el derecho de interrogar a la verdad acerca de sus efectos de poder, y al poder acerca de sus discursos de verdad ...” (Foucault, 1995, 8). Entonces, “... la desujeción de una política de la verdad supone un juego entre uno mismo y lo que se establece de antemano como verdadero. (...) Por eso se trata de una dimensión ética o éticopolítica en donde se hace posible no solamente un diagnóstico adecuado de nuestro presente, sino también la 
transformación de lo que somos ..." (Vignale y AUTOR/A, 2016, 179-180). Ello supone, interrogar al juzgador, a la función judicial, como parte del discurso de verdad del poder: si continuamos persuadidos de que en el juez habita la posibilidad de efectuar, más allá de los límites impuestos por los materiales jurídicos, una interpretación determinada (progresista o conservadora) nos mantenemos dentro de una concepción economicista del poder según la cual el juez posee el poder de atribuir sentido a las normas.

La explicitación de las condiciones de aparición de cualquier discurso supone un ejercicio crítico que tiende a desestabilizar la concepción según la cual una producción discursiva (una sentencia en nuestro caso) se explica como mera sucesión de elementos teóricos o conceptuales como si su desarrollo fuese autónomo de los múltiples y heterogéneos procesos que la tornan posible. Por ello un enfoque crítico supondría, entre otras operaciones, la restitución de las condiciones sociales y políticas que estructuran el discurso en su producción y circulación. Ahora bien, el carácter político de toda producción discursiva no se resuelve meramente a nivel de la voluntad o deseos del agente que la emite sino, por el contario, de las condiciones sociales, económicas, culturales que la habilitan: es decir de las relaciones de fuerzas que operan en una formación social espacio temporal. Comprender el funcionamiento, siempre contingente, de esas relaciones de fuerzas permiten sopesar cuándo, cómo y hasta qué punto involucrarse con un ejercicio de crítica de los derechos que suponga desestabilizar su autoridad ético-política ... pero esa no es una pregunta que pueda articularse ni, de manera alguna, responderse acabadamente; ni de una vez para siempre: son los campos de fuerzas en acción los que nos permitirán ir delineando estrategias de intervención como prácticas de libertad, tanto individuales como colectivas.

\title{
THE DILEMMA OF LEGAL PROGRESSIVISM: ON THE RELEVANCE OF THE CRITICAL EXERCISE ABOUT LAW
}

\begin{abstract}
The present paper proposes a critical reflection about the dilemma of legal progressivism, as it was exposed by Duncan Kennedy in his well-known work "The Critique of Rights in Critical Legal Studies". To this end, I will suggest some theoretical limitations of Kennedy's developments and propose some problematizations about the possibility and necessity of a critical exercise on law, from a Foucauldian perspective, with special attention to power relations, govern and conduction of conducts.
\end{abstract}

Keywords: Critique; Juridical Progressivism; Interpretation; Judicial Decision; Governmentality.

\section{Bibliografia}

ALVAREZ, Luciana. Conflictos y función judicial en el diagrama neoliberal. Actas de las VII Jornadas de Debates 
Actuales de Teoría Política Contemporánea. Buenos Aires: Debates Actuales de Teoría Política Contemporánea, 2016.

Judicialización de la política y soberanía popular: sobre el estatuto político de las resoluciones judiciales. Revista Crítica de Ciências Sociais, no 108. Portugal: Centro de Estudos Sociais da Universidade de Coimbra, Portugal, 2015, pp. 95-110.

DELEUZE, Gilles. El poder. Curso sobre Foucault. Buenos Aires: Cactus, 2014.

FOUCAULT, Michel. Historia de la sexualidad. Vol. 1. La voluntad de saber. Buenos Aires: Siglo XXI, 1977.

"Crítica y Aufklärung ["Qu’est-ce que la Critique?"]". Daimon. Revista Internacional de Filosofía, 11, 1995, pp. 5-25. Traducción de Jorge Dávila.

Vigilar y castigar: nacimiento de la prisión, Buenos Aires: Siglo XXI Editores Argentina, 2002.

Nacimiento de la biopolítica, FCE: Buenos Aires, 2007.

KENNEDY, Duncan. Libertad y restricción en la decisión judicial. El debate con la teoría crítica del derecho CLS. Bogotá: Siglo del hombre editores, 1999.

The Crittique of Rights in Critical Legal Studies. En.: Brown, W., Halley, J, Left Legalism/Left Critique, Durham: Duke University Press, 2002.

La crítica de los derechos en los Critical Legal studies. Revista Jurídica, Universidad de Palermo, № 7, 1, julio 2006. Trad. al español: Bertomeu, Juan Gonzalez. Disponible en http://www.palermo.edu/derecho/publicaciones/pdfs/revista_juridica/n7N1-Julio2006/071Juridica02.pdf.

LEMKE, Thomas. Foucault, Governmentality, and Critique. New York: Paradigm Publishers, 2012.

MARÍ, Enrique. "Moi, Pierre Rivière ... y el mito de la uniformidad semántica en las ciencias jurídicas y sociales". En.: Legendre, P. y otros. El discurso jurídico, Buenos Aires: Hachette, 1982.

VIGNALE, Silvana y AUTOR/A. Gubernamentalidad y contraconductas: actitud crítica como práctica de resistência. Revista Barda, No2, Centro de Estudios en Filosofia de la Cultura, UNComahue, 2016, pp. 164-182.

Trabalho enviado em 17 de setembro de 2017.

Aceito em 15 de outubro de 2017. 